\title{
Single-dose desloratadine and montelukast and allergen-induced late airway responses
}

\author{
B.E. Davis*\#, C. Illamperuma\#, G.M. Gauvreau`, R.M. Watson`, P.M. O’Byrne`, \\ F. Deschesnes ${ }^{+}$, L.P. Boulet ${ }^{+}$and D.W. Cockcroft*,\#
}

ABSTRACT: Montelukast and desloratadine synergistically inhibit the allergen-induced early asthmatic response. Montelukast also suppresses the allergen-induced late asthmatic response, but there are no reports on the effect of desloratadine or the combination on the allergen-induced late asthmatic response.

Atopic asthmatics $(n=10)$ completed a multicentric randomised double-blind crossover study comparing single-dose placebo, $5 \mathrm{mg}$ desloratadine, $10 \mathrm{mg}$ montelukast and the combination administered $2 \mathrm{~h}$ prior to allergen inhalation challenge. Methacholine challenges were performed $24 \mathrm{~h}$ before and after allergen challenge. Exhaled nitric oxide measurements and sputum inflammatory cell counts were also carried out.

All active treatments significantly decreased the late asthmatic response area under the curve. Combination therapy provided the greatest inhibition compared to desloratadine and montelukast. Montelukast was nonsignificantly better than desloratadine but not as effective as the combination. There was a trend towards a decrease in airway responsiveness following montelukast and combination. Montelukast, but not desloratadine or the combination, decreased exhaled NO levels $24 \mathrm{~h}$ after allergen. The allergen-induced increase in sputum eosinophil numbers was significantly suppressed at $7 \mathrm{~h}$ with desloratadine and combination therapy, and at $24 \mathrm{~h}$ with montelukast and combination therapy.

Single-dose co-administration of desloratadine and montelukast $2 \mathrm{~h}$ prior to allergen inhalation clinically abolished the late asthmatic response and eosinophil recruitment.

KEYWORDS: Antihistamine, antileukotriene, asthma, eosinophil, inflammation, sputum

T he airway response to inhaled allergen is characterised by airflow obstruction that is usually maximal within $20-30 \mathrm{~min}$ of exposure. This is referred to as the early asthmatic response (EAR), which results from immunoglobulin (Ig)-E-mediated mast cell degranulation, release of stored mediators (e.g. histamine) and newly synthesised mediators (e.g. leukotrienes) that subsequently exert their effects on surrounding tissues, causing bronchoconstriction, plasma exudation and mucus hypersecretion. The late asthmatic response (LAR), which occurs in $\sim 50 \%$ of individuals with a positive allergen challenge, is a subsequent episode of airflow obstruction that develops over the 4-8 $\mathrm{h}$ after the EAR has spontaneously resolved. The mechanism of the LAR is not fully understood, but immune responses and inflammation play a major role.

Synergistic inhibition of the EAR with the combination of an antihistamine (desloratadine) and a leukotriene receptor antagonist (montelukast) has been documented [1], and we subsequently hypothesised that this combination would also prove beneficial against the LAR, since the LAR is correlated with the EAR and allergen-induced airway inflammation, and since recent data suggest that these agents may have a role in immune and inflammatory responses.

\section{METHODS}

\section{Study design}

A randomised double-blind four-way crossover placebo-controlled multicentric allergen inhalation challenge investigation was conducted. Assessments were made of exhaled nitric oxide (eNO) levels and airway hyperresponsiveness, and sputum samples were collected at various time-points. All sites used the same standardised methodology for all assessments. The study was registered on ClinicalTrials.gov (NCT00424580). The Saskatoon Health Region Pharmacy Research Unit at the Royal University Hospital (Saskatoon, SK, Canada) provided currently available tablets of desloratadine and montelukast encapsulated with lactose filler in order to produce
AFFILIATIONS

*Dept of Pharmacology, College of

Medicine, University of

Saskatchewan, and,

\#Division of Respirology, Dept of

Medicine, Royal University Hospital,

University of Saskatchewan,

Saskatoon, SK,

-Dept of Medicine, McMaster

University, Hamilton, $\mathrm{ON}$, and

${ }^{+}$Institut de cardiologie et de

pneumologie de l'Universite Laval,

Hôpital Laval, Quebec City, QC,

Canada.

CORRESPONDENCE

B.E. Davis

Division of Respiratory Medicine

University of Saskatchewan

5th Floor Ellis Hall

103 Hospital Drive

Saskatoon

SK S7N OW8

Canada

Fax: 13069668694

E-mail: beth.davis@usask.ca

Received:

November 072008

Accepted after revision:

December 192008

SUPPORT STATEMENT

This study is registered at

ClinicalTrials.gov (trial number

NCT00424580)

STATEMENT OF INTEREST

Statements of interest for L.P. Boulet, D.W. Cockroft and P.M. O'Byrne can be found at www.erj.ersjournals.com/ misc/statements.dtl 
identical-looking treatments. Individual treatments were provided to subjects on day 1 of each treatment arm in a small brown sealed envelope. Subjects were instructed to ingest the contents of the envelope $2 \mathrm{~h}$ prior to allergen challenge, which was scheduled at $\geqslant 10$-day intervals.

\section{Subjects}

The subjects either were known dual responders or had undergone screening allergen challenges in order to assess eligibility. Subjects (table 1) were recruited to the study providing the following criteria had been met: baseline forced expiratory volume in $1 \mathrm{~s}(\mathrm{FEV} 1)$ of $\geqslant 70 \%$ of the predicted value; methacholine provocative concentration causing a $20 \%$ fall in FEV1 (PC20) of $\leqslant 16 \mathrm{mg} \cdot \mathrm{mL}^{-1}$; positive skin test to a common aeroallergen; EAR of $\geqslant 20 \%$ fall in FEV1 and LAR of $\geqslant 15 \%$ fall in FEV1; no respiratory infection or change in allergen exposure for 4 weeks prior to enrolment and throughout the investigation; and salbutamol $(n=10)$ had been withheld for $\geqslant 6 \mathrm{~h}$ prior to testing. One subject was using inhaled corticosteroid and one was using nasal corticosteroid, both on a stable dose prior to and throughout the study. The protocol was approved by the research ethics board of each institution, and all subjects provided written consent prior to the conduct of any study-related procedures.

\section{Allergen inhalation challenge}

Serial 2-fold dilutions were prepared from standardised stock allergens (grass, cat and house dust mite (Dermatophagoides pteronyssinus and Dermatophagoides farinae)) and diluted in normal saline. Starting concentrations for inhalation were determined by algebraic prediction of allergen PC20 using the skin test end-point and methacholine PC20 [2]. Allergen challenges began at the same concentration and the same number of concentrations were administered, within a given individual, for each allergen challenge (i.e. the same dose of allergen was administered following each treatment). Allergens were aerosolised via a Wright nebuliser (Roxon medi-tech, Montreal, PQ, Canada) calibrated to deliver $0.13 \mathrm{~mL} \cdot \mathrm{min}^{-1}$. Each concentration was inhaled during $2 \mathrm{~min}$ of tidal breathing via a mouthpiece and with nose clips in place. Two technically acceptable FEV1 manoeuvres were performed $60 \mathrm{~s}$ apart $10 \mathrm{~min}$ after each inhalation was complete. Once the EAR was captured, the response remained untreated and the FEV1 was assessed at various standardised time-points, up to $7 \mathrm{~h}$ after allergen inhalation, in order to capture the LAR [3]. The area under the curve (AUC) for the EAR and LAR were calculated using the trapezoid rule.

\section{Methacholine challenge}

Methacholine challenges were performed $24 \mathrm{~h}$ before and $24 \mathrm{~h}$ after the allergen inhalation challenge using a standardised 2min tidal breathing method $[4,5]$. All methacholine challenges were performed in an identical manner (i.e. same starting concentration) within a given subject. The PC20 was extrapolated if a concentration of $\leqslant 16 \mathrm{mg} \cdot \mathrm{mL}^{-1}$ resulted in a fall in FEV 1 of $>17 \%$ but $<20 \%$ [6], and interpolated if the fall was $>20 \%$ [7]. Methacholine challenges were followed by the administration of $200 \mu \mathrm{g}$ salbutamol.

\section{Sputum collection and analysis}

Sputum was collected $24 \mathrm{~h}$ before and 7 and $24 \mathrm{~h}$ after allergen challenge. Sputum collection and processing were performed using the methodology of PIZZICHINI et al. [8]. In brief, subjects inhaled, via mouthpiece, increasing concentrations $(3,4$ and $5 \%$, each for $7 \mathrm{~min}$ ) of hypertonic saline, aerosolised by a highoutput ultrasonic nebuliser. Collected specimens were immediately refrigerated and processed within $2 \mathrm{~h}$ of collection. Total cell counts were determined using a Neubauer haemocytometer chamber (Hausser Scientific, Horsham, PA, USA) and expressed as the number of cells per millilitre of sputum. Differential cell counts were performed, under blinded conditions, from cytospin preparations stained with Diff Quik (Dade Behring, Newark, DE, USA).

\section{TABLE 1 Patient demographics}

\begin{tabular}{|c|c|c|c|c|c|c|c|c|c|}
\hline $\begin{array}{l}\text { Subject } \\
\text { no. }\end{array}$ & Sex & $\begin{array}{l}\text { Age } \\
\text { yrs }\end{array}$ & Height $\mathrm{cm}$ & $\begin{array}{c}\text { Baseline FEV1 } \\
\text { L }\end{array}$ & $\begin{array}{c}\text { Baseline FEV1 } \\
\% \text { pred }\end{array}$ & Allergen & $\begin{array}{l}\text { Allergen } \\
\text { dilution" }\end{array}$ & $\begin{array}{c}\text { Methacholine } \mathrm{PC}_{20} \\
\mathrm{mg} \cdot \mathrm{mL}^{-1}\end{array}$ & Medication \\
\hline 2 & $\mathrm{~F}$ & 24 & 155 & 3.29 & 106 & HDM (Dp) & $1: 256$ & 2.5 & Salb \\
\hline 3 & M & 30 & 178 & 3.41 & 77 & Cat & $1: 256$ & 0.34 & Salb \\
\hline 4 & M & 25 & 180 & 4.25 & 91 & Grass & $1: 64$ & 1.4 & Salb \\
\hline 7 & $M$ & 58 & 180 & 3.44 & 90 & Cat & $1: 128$ & 1.3 & Salb \\
\hline 8 & $F$ & 26 & 165 & 3.75 & 110 & HDM (Df) & $1: 64$ & 11.7 & Salb \\
\hline 9 & $M$ & 23 & 183 & 5.22 & 107 & Cat & $1: 32$ & 5.3 & Salb \\
\hline 10 & $\mathrm{~F}$ & 44 & 173 & 3.72 & 122 & Cat & $1: 4$ & 5.6 & Salb/flonase \\
\hline Mean \pm SD & & $36.1 \pm 14.8$ & $173.5 \pm 9.7$ & $3.55 \pm 0.81$ & $93.2 \pm 17.3$ & & & $2.27^{\circ}$ & \\
\hline
\end{tabular}

Flonase was given at a dose of 2 squirts.nare ${ }^{-1} \cdot$ day $^{-1}$. FEV 1 : forced expiratory volume in $1 \mathrm{~s}$; \% pred: \% predicted; PC20: provocative concentration of methacholine causing a $20 \%$ fall in FEV1; M: male; F: female; HDM: house dust mite; Dp: Dermatophagoides pteronyssinus; Df: Dermatophagoides farinae; Salb: salbutamol p.r.n.; Bud: budesonide $400 \mu \mathrm{g} \cdot$ day $^{-1}$. \#: final concentration administered; ": geometric mean. 


\section{Exhaled nitric oxide}

eNO measurements were performed $24 \mathrm{~h}$ before and 4, 7 and $24 \mathrm{~h}$ after allergen challenge following American Thoracic Society recommendations [9]. Subjects performed an inhalation to total lung capacity via a filter/mouthpiece followed by exhalation at a constant flow rate of $50 \mathrm{~mL} \cdot \mathrm{s}^{-1}$ until the reading was captured. Comparisons were made using the mean of three measurements at each time-point.

\section{Data analysis}

Two-way (subject/treatment) ANOVA, followed by pairwise comparison of means (least squared difference) if applicable (Statistix version 7.0; Analytical Software, Tallahassee, FL, USA) was used to examine differences in the end-points under investigation. The study was appropriately (>80\%) powered, with 10 subjects, to detect differences in the primary end-point (LAR of $50 \%$ inhibition in AUC), and in the secondary endpoints (EAR, allergen-induced airway hyperresponsiveness and sputum eosinophil cell counts) [10,11]. The appropriate sample size for achieving $\geqslant 80 \%$ power in detecting a significant change in eNO level is unknown.

\section{RESULTS}

All 10 randomised subjects completed the study without incident. Desloratadine, montelukast and the combination all significantly decreased the LAR FEV1 AUC in a treatmentdependent manner $(\mathrm{p}<0.001$ (ANOVA)). Desloratadine reduced the response by $43 \%$, montelukast reduced it by $71 \%$ and the combination completely blocked the response (fig. 1). Desloratadine, montelukast and the combination also significantly reduced the mean EAR AUC by 32, 72 and 100\%, respectively. The inhibition with combination, however, was not significantly different from that of montelukast alone for the EAR $(p=0.052)$. The mean percentage fall in FEV1 at various time-points following allergen challenge is shown in figure 2 . The mean \pm SEM doubling dose increase in methacholine PC20 was $0.66 \pm 0.19$ after placebo, $0.82 \pm 0.26$ after desloratadine, $0.31 \pm 0.21$ after montelukast and $0.18 \pm 0.23$

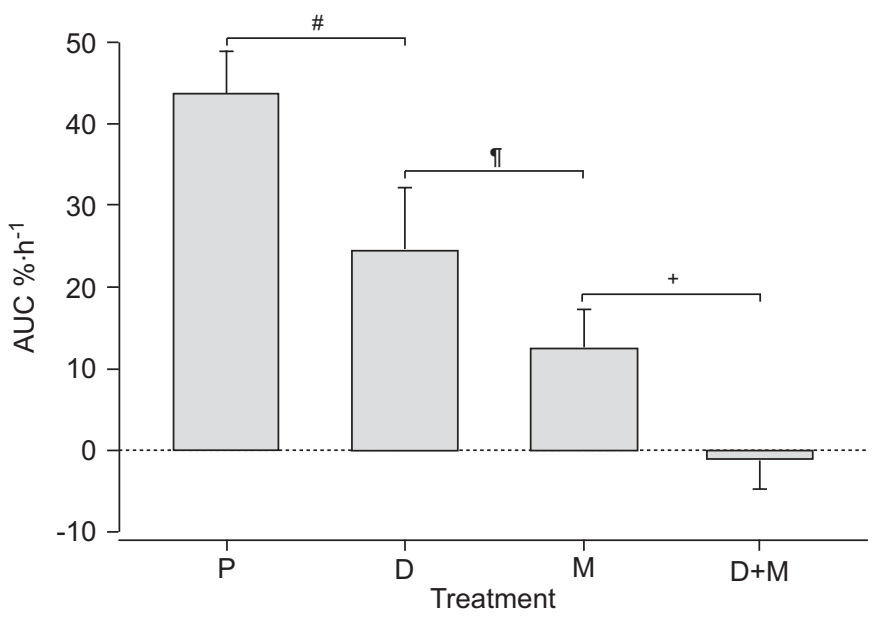

FIGURE 1. Treatment-dependent inhibition of the late asthmatic response (LAR) expressed as mean area under the forced expiratory volume in $1 \mathrm{~s}$ curve (AUC) 3-7 h after allergen inhalation $(n=10)$. All treatments significantly decreased the LAR. The difference between desloratadine (D) and montelukast (M) was nonsignificant. P: placebo. ${ }^{*}: p=0.007 ;{ }^{\bullet}: p=0.066 ;^{+}: p=0.042$ after combination $(p=0.092$ (ANOVA)) (fig. 3a). Sputum eosinophil numbers increased by $23.2 \% 7 \mathrm{~h}$ after allergen inhalation in the untreated arm, whereas the increase following desloratadine was only $10.5 \%$ and after combination only $2.8 \%(\mathrm{p}<0.05)$. At $24 \mathrm{~h}$ after allergen challenge, the increase in sputum eosinophils was $8.8 \%$ following montelukast and $4.5 \%$ after combination versus $16.2 \%$ after placebo $(p<0.05)$. The difference between the individual therapies and combination was not significant at either time-point (fig. 4). The allergeninduced increase in eNO concentration was significantly less after montelukast treatment only and only at the 24-h timepoint $(p=0.03)$ (fig. 3b).

\section{DISCUSSION}

The present in vivo investigation provides new insights into the effects of desloratadine, montelukast and the combination in individuals with mild atopic asthma and a dual asthmatic response. Few clinical studies have investigated the effects of combining a leukotriene antagonist with an antihistamine on the airway response to allergen, and none have looked at a single dose (table 2). Loratadine, the parent compound of desloratadine, has been shown by ROQUET et al. [12] to significantly decrease the LAR alone and in combination with zafirlukast following 1 week of high-dose therapy (twice the daily recommended dose of both drugs). The present study has shown that desloratadine, in a single dose, provides the same magnitude of bronchoprotection against the LAR as in this previous study of higher dose and longer duration. Comparison of the leukotriene antagonists suggests that a single dose of montelukast is also more effective than multiplehigh-dose zafirlukast. The present study also documents complete inhibition of the LAR with the combination of montelukast and desloratadine, whereas the study of RoQUET et al. [12] showed only $75 \%$ inhibition of the LAR following the combination of zafirlukast and loratadine. Similarly, a more recent investigation using clinically relevant doses of azelastine and montelukast for 1 week also showed less of an effect compared with the present results [13]. The differences between the present study and these two previous studies may be related to the pharmacokinetic and pharmacodynamic

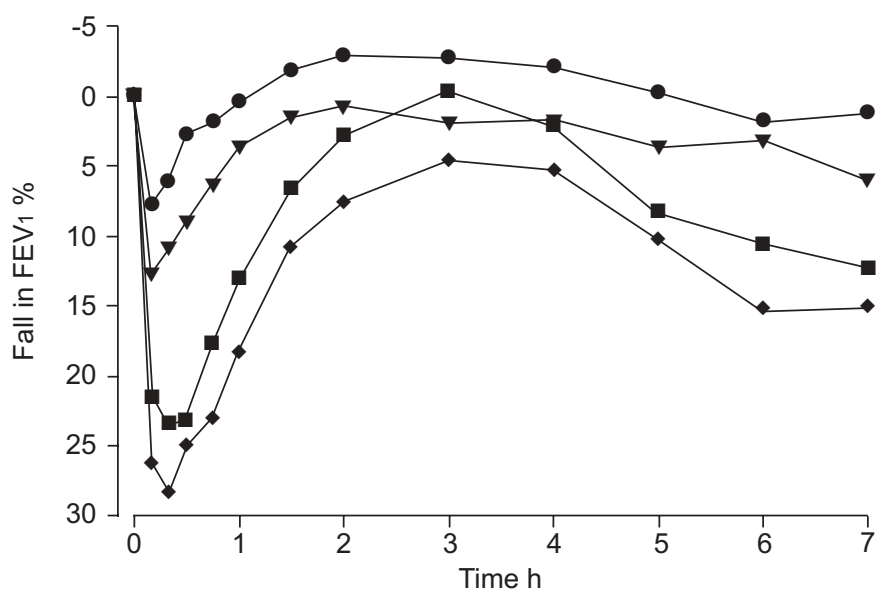

FIGURE 2. Mean fall in forced expiratory volume in $1 \mathrm{~s}$ (FEV 1$)$ over the $7 \mathrm{~h}$ following allergen inhalation for each treatment arm ( $\mathbf{\square}$ : desloratadine (D); $\boldsymbol{\nabla}$ montelukast (M); $\bullet$ : D and $\mathrm{M}$; : placebo). $\mathrm{p}<0.00001$ (ANOVA; $\mathrm{n}=10$ ). 

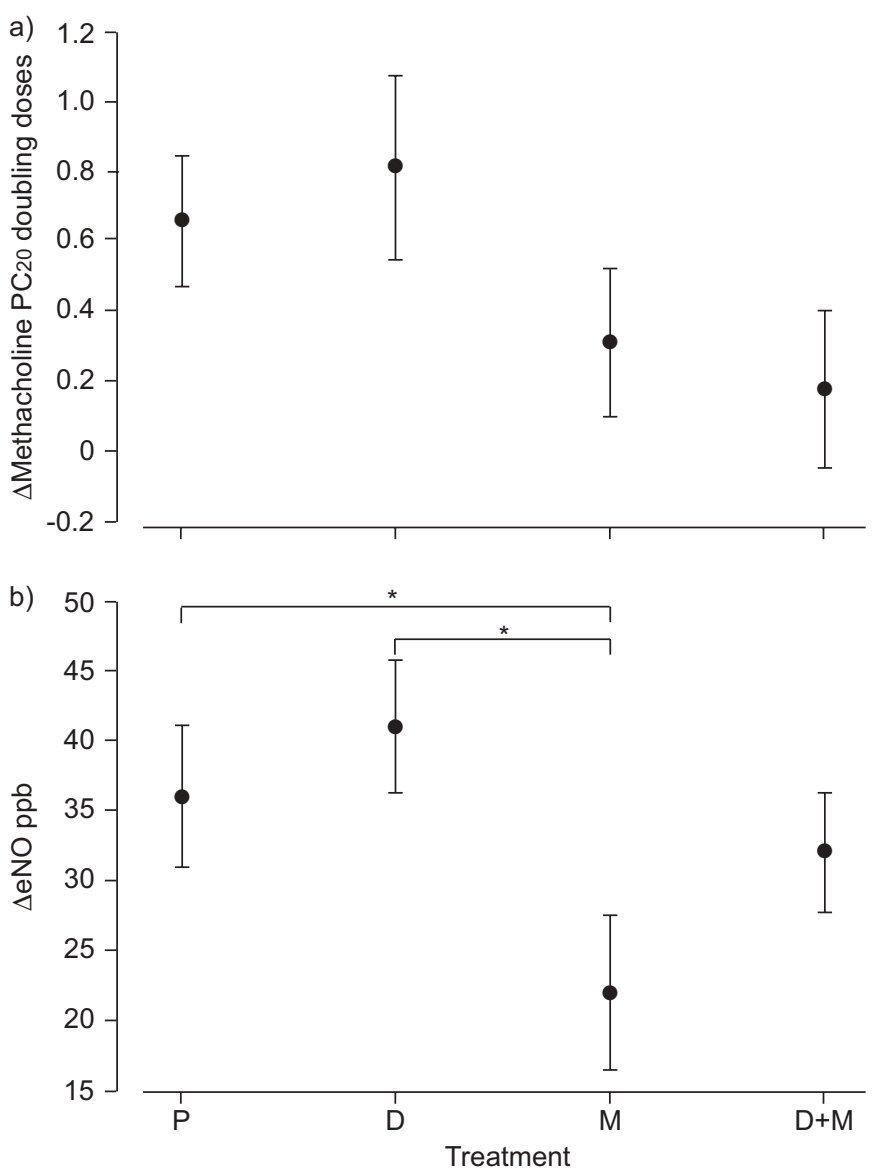

FIGURE 3. a) Airway responsiveness to methacholine expressed as the dose shift $(\Delta)$ in provocative concentration causing a $20 \%$ fall in forced expiratory volume in $1 \mathrm{~s}\left(\mathrm{PC}_{20}\right)$ from $24 \mathrm{~h}$ prior to allergen challenge to $24 \mathrm{~h}$ after allergen challenge. Active treatments did not have an effect on the allergen-induced increase in airway responsiveness. A trend is apparent with montelukast $(\mathrm{M})$ and combined desloratadine (D) and $\mathrm{M}$ therapy. $\mathrm{p}=0.092$ (ANOVA; $n=10$ ). b) Mean absolute change $(\Delta)$ in exhaled nitric oxide (eNO) levels $24 \mathrm{~h}$ after allergen inhalation. Pretreatment with $\mathrm{M}$ resulted in less of an increase than with both placebo $(P)$ and D. *: $p<0.05 ; p=0.033$ (ANOVA; $n=10$ ).

properties of the therapies, allergen challenge methodologies or study design, or may even suggest the development of tachyphylaxis or the onset of tolerance following the longer and higher dosing regimen.

An earlier report documented synergistic inhibition of the EAR with combination therapy that was superior to that of either monotherapy. Montelukast also inhibited the response but desloratadine alone had no effect. Early-response methodology permits the assessment of the response as a doubling-dose shift in allergen PC20 [1]. The present study now documents that a single dose of desloratadine significantly inhibits the EAR, assessed as the AUC, as does a single dose of montelukast. The combination completely blocked the response, but did not differ from montelukast monotherapy. If the effects were further assessed as changes in maximal fall in FEV1 (table 2), the inhibition of the response would be $14 \%$ with desloratadine (nonsignificant), 54\% with montelukast and 73\% with the combination (both significant and no difference between treatments). It should be apparent that the different methods
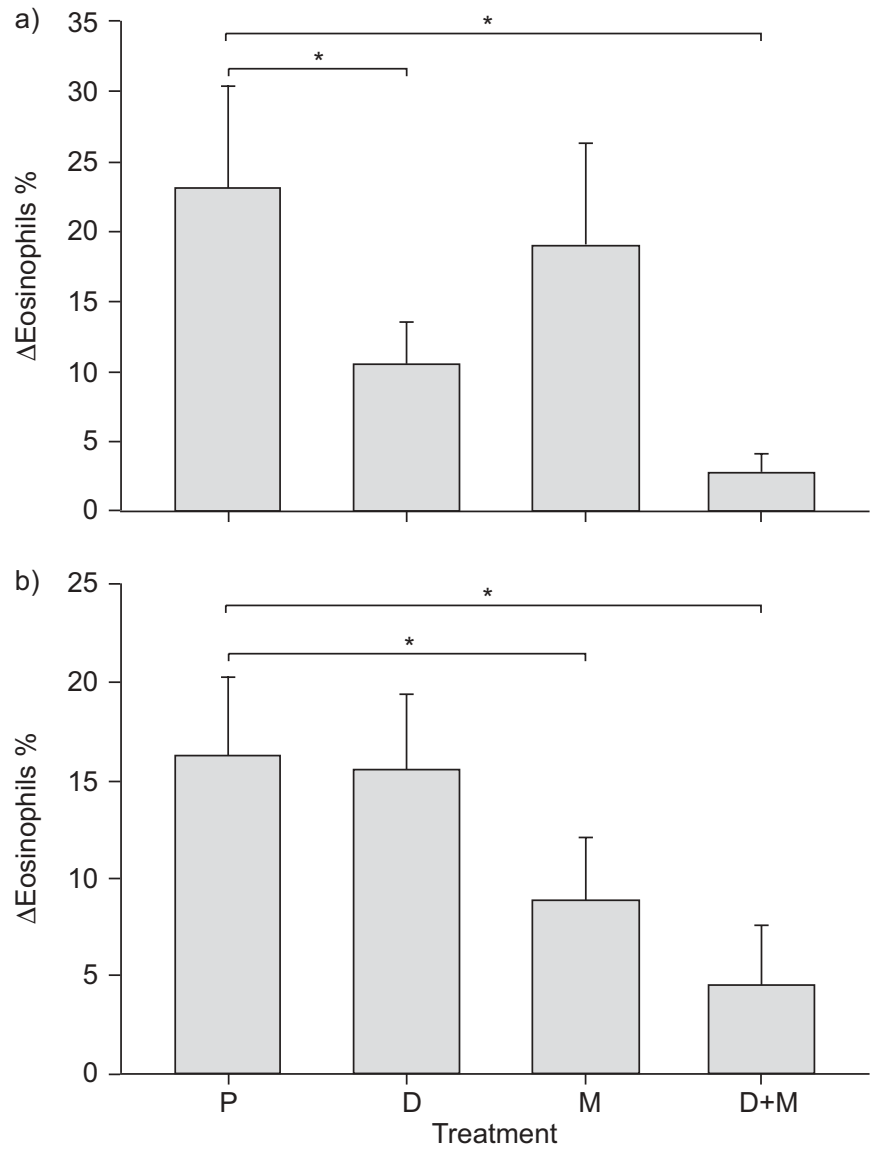

FIGURE 4. Increase $(\Delta)$ in sputum eosinophils following allergen inhalation at a) $7 \mathrm{~h}$; and b) $24 \mathrm{~h}$. a) Pretreatment with desloratadine (D) and combined D and montelukast $(\mathrm{M})$ therapy $2 \mathrm{~h}$ before allergen inhalation resulted in a significantly reduced increase in sputum eosinophil numbers at $7 \mathrm{~h}(\mathrm{p}=0.006$ (ANOVA; $n=10)$ ). b) Pretreatment with $\mathrm{M}$ and combination therapy resulted in a significantly reduced increase in sputum eosinophils at $24 \mathrm{~h}(\mathrm{p}=0.036$ (ANOVA; $\mathrm{n}=10)$ ). P: placebo. * $p<0.05$.

of assessment produce non-equivalent results of equivocal statistical significance, which is most probably the result of the recovery phase of the EAR. Comparison of EAR data and EAR data from an LAR design is therefore difficult.

Direct histamine $\mathrm{H}_{1}$ receptor and cysteinyl leukotriene receptor 1 antagonism at the level of the airway smooth muscle is an obvious potential mechanism for preventing the bronchoconstriction associated with the LAR by blocking the action of mediators (i.e. histamine and leukotrienes) released by recruited inflammatory cells (e.g. eosinophils and basophils). However, the single-dose design, pharmacokinetic and pharmacodynamic properties of the drugs and the response to combination therapy render this rationale unlikely as the mechanism responsible for the inhibition of the LAR.

Both histamine [14] and the leukotrienes [15] play a role in leukocyte recruitment, and, indeed, evidence is provided here of a decrease in sputum eosinophil numbers with desloratadine and the combination at $7 \mathrm{~h}$ and montelukast and the combination at $24 \mathrm{~h}$. A trend of increased efficacy with combination therapy is apparent, but the difference between 


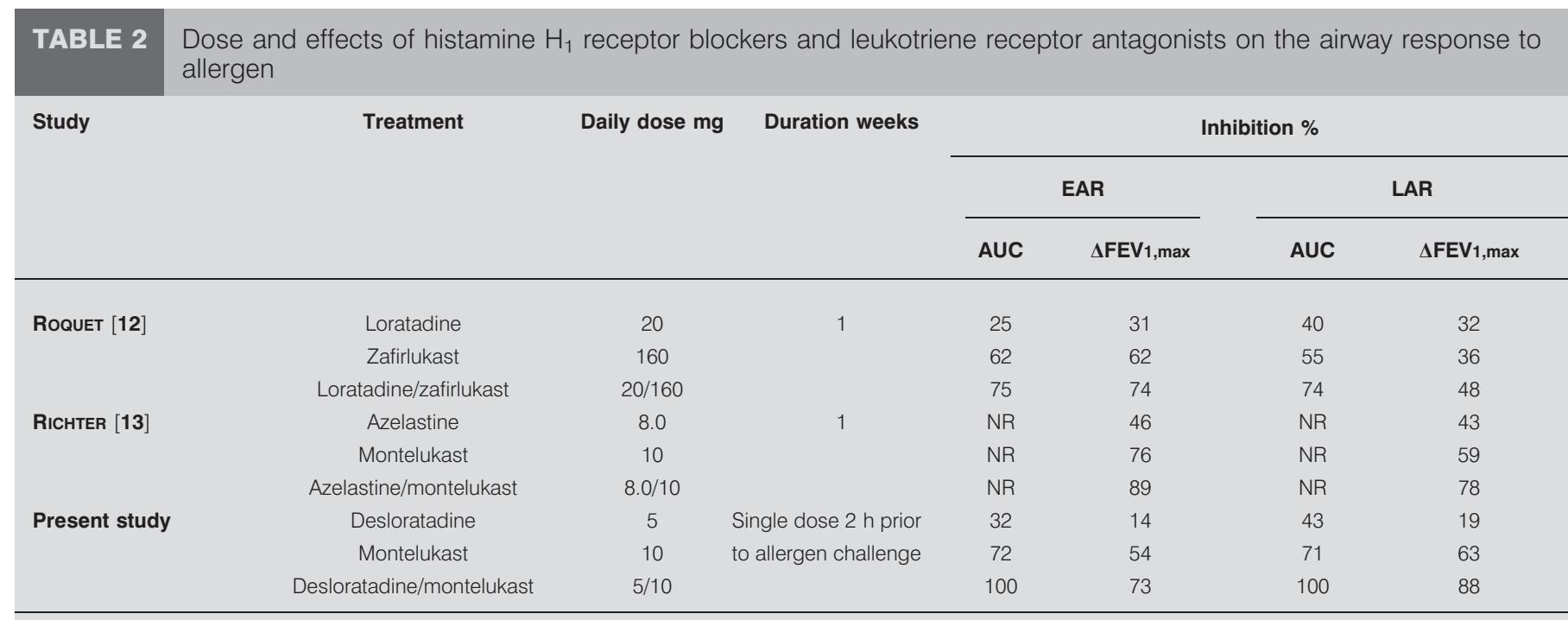

EAR: early asthmatic response; LAR: late asthmatic response; AUC: area under the forced expiratory volume in $1 \mathrm{~s}(\mathrm{FEV} 1)$ curve; $\Delta \mathrm{FEV} 1$, max: maximal decrease in FEV1; NR: not reported.

the two monotherapies and the combination therapy at the two time-points is not significant. Earlier investigations have shown leukotriene antagonists to significantly reduce eosinophil trafficking to the airway following allergen inhalation. LEIGH et al. [16] documented less of an increase in sputum eosinophil numbers following 10 days of $10 \mathrm{mg} \cdot \mathrm{day}^{-1} \mathrm{mon}-$ telukast at both 7 and $24 \mathrm{~h}$ following allergen challenge, and PARAMESWARAN et al. [17] also showed leukotriene inhibition of sputum eosinophil numbers at 7 and $24 \mathrm{~h}$ after allergen inhalation following 2 weeks of pranlukast. There is at least one report documenting no change in allergen-induced sputum eosinophilia following montelukast [18]; however, it is difficult to directly compare the present data with those of the study of DiAmANT et al. [18] due to the different dosing regimens and study design.

Increased responsiveness to directly acting stimuli (e.g. methacholine) is another hallmark of the LAR to allergen. The increase in airway responsiveness following placebo (i.e. decrease in methacholine PC20) $24 \mathrm{~h}$ after allergen inhalation was unaffected by all active treatments. This is the first report of the effects of desloratadine on allergen-induced changes in methacholine $\mathrm{PC} 20$, and the present results are consistent with previous investigations, which have shown no change in airway responsiveness following allergen exposure and pretreatment with a $\mathrm{H}_{1}$ blocker $[19,20]$. The literature surrounding the effect of leukotriene antagonists on allergen-induced changes in methacholine responsiveness is controversial. PALMQVIST et al. [21] documented no change in methacholine PC20 following 8 days of montelukast monotherapy; conversely, however, $10 \mathrm{mg} \cdot$ day $^{-1}$ montelukast for 10 days decreased the response, as shown by LEIGH et al. [16], and $300 \mathrm{mg}$ b.i.d. pranlukast for 2 weeks also prevented the allergen-induced increase in airway responsiveness to methacholine, as shown by PARAMSEWARAN et al. [22]. TAYLOR and O'SHAUGHNESSY [23] have also shown an inhibitory effect on the allergen-induced increase in airway responsiveness to histamine following single-dose administration of a leukotriene receptor antagonist
(ICI204.219; developed as zafirlukast) given $2 \mathrm{~h}$ prior to allergen challenge. Although the present investigation is similar to that of TAYLOR and O'SHAUGHNESSY [23] (i.e. single dose administered $2 \mathrm{~h}$ prior to allergen challenge), direct comparison is difficult due to the choice of directly acting agent (i.e. histamine versus methacholine) and differences in the times that the measurements were made. Most allergen challenge studies assess this parameter using $24 \mathrm{~h}$ before/after allergen challenge data. In the study of TAYLOR and O'SHAUGHNESSY [23], measurements were made $\sim 3 \mathrm{~h}$ before and $7 \mathrm{~h}$ after allergen challenge.

The relationship between airway inflammation and airway hyperresponsiveness following allergen exposure remains unclear. The present data support a relationship between these parameters in that a reduction in sputum eosinophil numbers parallels a trend towards a significant decrease in airway hyperresponsiveness with montelukast and the combination at the 24-h time-point. Additionally, at this time-point, desloratadine did not affect eosinophil recruitment and there was no change in the increase in airway responsiveness to direct stimuli. Although interpretation would have been difficult (smaller airway calibre compared to the pre-measurement comparator due to the presence of the LAR), it would have been interesting to have measured the methacholine PC20 at the 7-h time-point.

With the exception of montelukast, which significantly suppressed the allergen-induced increase in eNO levels at the 24-h measurement, there were no treatment effects on this parameter. The amount of eNO has been shown to increase following allergen exposure [24], and has been reported to correlate with the degree of eosinophilic inflammation [25]. Even though desloratadine reduced eosinophil influx, $\mathrm{H}_{1}$ antagonism did not affect eNO at $7 \mathrm{~h}$, suggesting that the source of eNO at this time-point might not be eosinophilic in nature. Conversely, a reduction in eosinophil numbers following montelukast is indeed associated with a reduction in eNO 
concentration at $24 \mathrm{~h}$. The temporally associated differences are interesting and may be related to the kinetics of eosinophil activation. It may also be worth noting that eNO levels are higher, although not significantly, following antihistamine, and this is perhaps reflected in the observed effect following combination (i.e. less than montelukast alone). Relative to bronchial biopsy and bronchial lavage, eNO measurement is an attractive noninvasive procedure for assessing airway inflammation and therapeutic efficacy when incorporated into the allergen challenge model. However, the reported lack of specificity and selectivity may limit the validity and interpretation of the data [26]. It must also be acknowledged that the present study may not be appropriately powered to detect a significant change in eNO concentration.

The biological role of histamine in the pathogenesis of asthma is, once again, an area of great interest. Many of the cells involved in the inflammatory process and the immune response possess histamine and/or leukotriene receptors. In addition to leukocyte recruitment, histamine may have a role in regulating the phenotype of dendritic cells and T-cells [27], direct T-cell trafficking [28] and influence cytokine signalling [29]. Whether or not any of these potential mechanisms can explain the present results needs to be investigated.

It is well documented that histamine and the leukotrienes are indeed important in the manifestation of the EAR. The current investigation provides clinical evidence that these mediators alone, but to a greater extent in combination, are also important in orchestrating the LAR. Current therapeutic options for suppressing the LAR include long-acting $\beta_{2^{-}}$ agonists (short-acting if used following the EAR), single-dose inhaled glucocorticosteroids, combination therapies such as Symbicort $_{\circledR}$ and $\operatorname{Advair}$, and anti-IgE. Importantly, however, there is a subpopulation of individuals with atopic asthma who are treated only with infrequent short-acting bronchodilators. Although the relief provided by the use of rescue bronchodilators is beneficial, prophylactic prevention versus masking the response with functional antagonism is perhaps preferred. It is, therefore, these individuals who may benefit from combined desloratadine and montelukast therapy when exposure to a triggering allergen is imminent.

In summary, concurrent, single-dose administration of desloratadine and montelukast blocks the airway response to inhaled allergen for $\geqslant 7 \mathrm{~h}$ and suppresses eosinophil influx for up to $24 \mathrm{~h}$. Future investigations regarding potential mechanisms are of significant interest.

\section{REFERENCES}

1 Davis BE, Todd DC, Cockcroft DW. Effect of combined montelukast and desloratadine on the early asthmatic response to inhaled allergen. J Allergy Clin Immunol 2005; 116: 768-772.

2 Cockcroft DW, Davis BE, Boulet LP, et al. The links between allergen skin test sensitivity, airway responsiveness and airway response to allergen. Allergy 2005; 60: 56-59.

3 Boulet LP, Gauvreau G, Boulay ME, et al. The allergen bronchoprovocation model: an important tool for the investigation of new asthma anti-inflammatory therapies. Allergy 2007; 62: 1101-1110.
4 Crapo RO, Casaburi R, Coates AL, et al. Guidelines for methacholine and exercise challenge testing - 1999. Am J Respir Crit Care Med 2000; 161: 309-329.

5 Cockcroft DW, Killian DN, Mellon JJA, et al. Bronchial reactivity to inhaled histamine: a method and clinical survey. Clin Allergy 1977; 7: 235-243.

6 Jokic R, Davis EE, Cockcroft DW. Methacholine PC20 extrapolation. Chest 1998; 114: 1796-1797.

7 Cockcroft DW, Murdock KY, Mink JT. Determination of histamine PC20: comparison of linear and logarithmic interpolation. Chest 1983; 84: 505-506.

8 Pizzichini E, Pizzichini MM, Efthimiadis A, et al. Indices of airway inflammation in induced sputum: reproducibility and validity of cell and fluid-phase measurements. Am J Respir Crit Care Med 1996; 154: 308-317.

9 Anon, Recommendations for standardized procedures for the online and offline measurement of exhaled lower respiratory nitric oxide and nasal nitric oxide in adults and children - 1999. Am J Respir Crit Care Med 1999; 160: 2104-2117.

10 Inman MD, Watson R, Cockcroft DW, et al. Reproducibility of allergen-induced early and late asthmatic responses. $J$ Allergy Clin Immunol 1995; 95: 1191-1195.

11 Gauvreau GM, Watson RM, Rerecich TJ, et al. Repeatability of allergen-induced airway inflammation. J Allergy Clin Immunol 1999; 104: 66-71.

12 Roquet A, Dahlen B, Kumlin M, et al. Combined antagonism of leukotrienes and histamine produces predominant inhibition of allergen-induced early and late phase airway obstruction in asthmatics. Am J Respir Crit Care Med 1997; 155: 1856-1863.

13 Richter K, Gronke L, Janicki S, et al. Effect of azelastine, montelukast, and their combination on allergen-induced bronchoconstriction in asthma. Pulm Pharmacol Ther 2008; 21: 61-66.

14 Thurmond RL, Gelfand EW, Dunford PJ. The role of histamine $\mathrm{H}_{1}$ and $\mathrm{H}_{4}$ receptors in allergic inflammation: the search for new antihistamines. Nat Rev Drug Discov 2008; 7: 41-53.

15 Busse W, Kraft M. Cysteinyl leukotrienes in allergic inflammation: strategic target for therapy. Chest 2005; 127: 1312-1326.

16 Leigh R, Vethanayagam D, Yoshida M, et al. Effects of montelukast and budesonide on airway responses and airway inflammation in asthma. Am J Respir Crit Care Med 2002; 166: 1212-1217.

17 Parameswaran K, Watson R, Gauvreau GM, et al. The effect of pranlukast on allergen-induced bone marrow eosinophilopoiesis in subjects with asthma. Am J Respir Crit Care Med 2004; 169: 915-920.

18 Diamant Z, Grootendorst DC, Veselic-Charvat M, et al. The effect of montelukast (MK-0476), a cysteinyl leukotriene receptor antagonist, on allergen-induced airway responses and sputum cell counts in asthma. Clin Exp Allergy 1999; 29: 42-51.

19 Twentyman OP, Ollier S, Holgate ST. The effect of $\mathrm{H}_{1}$ receptor blockade on the development of early and late phase bronchoconstriction and increased bronchial responsiveness in allergen-induced asthma. J Allergy Clin Immunol 1993; 91: 1169-1178. 
20 Bentley AM, Walker S, Hanotte F, et al. A comparison of the effects of oral cetirizine and inhaled beclomethasone on early and late asthmatic responses to allergen and the associated increase in airways hyperresponsiveness. Clin Exp Allergy 1996; 26: 909-917.

21 Palmqvist M, Bruce C, Sjostrand M, et al. Differential effects of fluticasone and montelukast on allergen-induced asthma. Allergy 2005; 60: 65-70.

22 Parameswaran K, Liang H, Fanat A, et al. Role for cysteinyl leukotrienes in allergen-induced change in circulating dendritic cell number in asthma. J Allergy Clin Immunol 2004; 114: 73-79.

23 Taylor IK, O'Shaughnessy KM. Effect of cysteinyl-leukotriene receptor antagonist ICI 204.219 on allergen-induced bronchoconstriction and airway hyperactivity in atopic subjects. Lancet 1991; 337: 690-694.

24 Duong M, Gauvreau G, Watson R, et al. The effects of inhaled budesonide and formoterol in combination and alone when given directly after allergen challenge. J Allergy Clin Immunol 2007; 119: 322-327.

25 Jatakanon A, Lim S, Kharitonov SA, et al. Correlation between exhaled nitric oxide, sputum eosinophils, and methacholine responsiveness in patients with mild asthma. Thorax 1998; 53: 91-95.

26 Pendharkar S, Mehta S. The clinical significance of exhaled nitric oxide in asthma. Can Respir J 2008; 15: 99-106.

27 Akdis CA, Blaser K. Histamine in the immune regulation of allergic inflammation. J Allergy Clin Immunol 2003; 112: 15-22.

28 Bryce PJ, Mathias CB, Harrison $\mathrm{KL}$, et al. The $\mathrm{H}_{1}$ receptor regulates allergic lung responses. J Clin Invest 2006; 116: 1624-1632.

29 Schneider E, Rolli-Derkinderen M, Arock M, et al. Trends in histamine research: new functions during immune responses and hematopoiesis. Trends Immunol 2002; 23: 255-263. 